\title{
HEMATOLOGICAL FINDINGS IN COVID-19 PATIENTS AT BIRAT MEDICAL COLLEGE TEACHING HOSPITAL
}

Mrinalini Singh, ${ }^{1}$ Santosh Upadhyay Kafle, ${ }^{1}$ Surya B. Parajuli, ${ }^{2}$ Neeta Kafle, ${ }^{1}$ Amrita Sinha, ${ }^{1}$ Randhir Kumar Singh ${ }^{3}$

\begin{abstract}
INTRODUCTION

The outbreak of 2019 novel corona virus has also affected the Nepalese population. Real Time-Polymerase Chain Reaction (RT-PCR) is the diagnostic laboratory test for confirming the diagnosis. The complete blood count (CBC) is the laboratory test routinely done in patients suffering from any type of infection. This test provides the information to physicians regarding the inflammatory process. The objective of this study was to evaluate and find out whether hematologic parameters are affected in a person suffering from Covid-19 infections.
\end{abstract}

\section{MATERIAL AND METHODS}

This is a prospective study done from $3^{\text {rd }}$ December 2020 to $3^{\text {rd }}$ February 2021 for a period of two months. All the confirmed patients of corona (COVID-19) with RT-PCR, between days-1 to day-15 of PCR positivity, whose hematological profile was sent to the pathology laboratory department, were studied. The hematologic parameters studied include total white blood cells count (TLC), differential white blood cell count (DLC), hemoglobin and platelet counts.

\section{RESULTS}

Out of one hundred (100) RT-PCR positive patients eighty (80\%) were male and twenty (20\%) were female. Age group of patients ranged from 27 years to 94 years. Ninety-four (94\%) patients reveal leukocytosis and Ninety-six (96\%) patients showed increased in differential neutrophil count. Fifty-two (52\%) patients reveal anemia and platelets count was normal in seventy-eight $(78 \%)$ cases.

\section{CONCLUSION}

Covid-19 infection causes changes in the hematological parameters. Study of these parameters provides significant clinical information.

\section{KEYWORDS}

Covid-19, Hematologic parameters, RT-PCR.

1. Department of Pathology, Birat Medical College and Teaching Hospital, Nepal

2. Department of Community Medicine, Birat Medical College and Teaching Hospital, Nepal

3. Department of Microbiology, Birat Medical College and Teaching Hospital, Nepal

DOI: http//doi.org/10.3126/jucms.v9i01.37977

\author{
For Correspondence \\ Dr. Mrinalini Singh \\ Department of Pathology \\ Birat Medical College and Teaching Hospital \\ Biratnagar, Nepal \\ Email:sdrmrinalini@gmail.com
}




\section{INTRODUCTION}

The ongoing pandemic of 2019 novel corona virus (SARS$\mathrm{CoV}-2$ ) which causes novel corona virus pneumonia (Covid19) affects various organ systems of the human body. The common clinical symptoms of SARS-CoV-2 (Covid-19) are fever, dry cough and dyspnea. Many people also suffer from diarrhea, fatigue, headache, loss of taste and smell. Though it is known that Covid-19 is principally manifested as a respiratory disease, but many data indicate that it should be considered as a systemic disease involving multiple systems, like hematopoietic, respiratory, gastrointestinal, cardio vascular and immune system. ${ }^{1,2}$

Searching the literatures show that in SARS-CoV-2 viral infections, and in other infectious diseases like influenza, dengue and acquired human immunodeficiency virus (HIV), hematological parameters are many of the times affected. ${ }^{3,4,5}$ It is also evident that Coronaviruses can cause alteration in normal hematopoiesis by infecting bone marrow cells. ${ }^{6}$ Without any medical interventions in many patients the disease may develop critical and fatal. Though studies were done in other parts of the world but there is no sufficient data about SARS-CoV-2 infection and hematologic parameters changes in Nepal.

Among various hematologic markers total leukocyte count (TLC) is used as an inflammatory marker. TLC value is increased in various infectious disorders. Neutrophils (the most common cell type among the white blood cells) and the lymphocytes (the second common cell type) take part in inflammatory processes. Circulating WBCs respond to stress by increasing neutrophils and reducing lymphocytes. Even, platelets are also an important regulator of various inflammatory processes. Thus, the study of these hematological parameters can help in the identification of patients to be admitted for special medical need care such monitoring into medical ward or intensive care unit. The study was therefore done to help the treating physician understanding the severity of the disease and pay special attention to the patients who need critical care management.

\section{MATERIAL AND METHODS}

This was a prospective study done from $3^{\text {rd }}$ December 2020 to $3^{\text {rd }}$ February 2021 after taking ethical clearance from Institutional Review Committee (IRC) of Birat Medical College and Teaching Hospital. The hematological profile sent to the Pathology laboratory department from day- 1 to day-15 of the diagnosed cases of corona was studied. Covid19 was confirmed with RT-PCR by detecting SARS-CoV-2 RNA in oro-nasopharyngeal swab samples. Demographic data and laboratory values were collected from patients' files and laboratory records. The hematologic parameters studied include total white blood cells count (TLC), differential white blood cell count (DLC) including differential neutrophils count, lymphocyte count, monocyte, eosinophils and also basophil count. Values of hemoglobin and platelet counts were also studied. All the values generated by complete hemogram automated analyzer Beckman Coulter DxH 500 available in laboratory were noted. All the parameters were confirmed and double checked by smear examination. The normal reference range of all hematologic parameters were undertaken according to Universal established ranges. The reference range for adults (males and females) for normal platelet count was taken as $150-400 \times 10^{9} / \mathrm{L}$ of whole blood. Normal range for total leukocytes count (TLC) was taken as 4.00-11.0 $\times$ $10^{9} / \mathrm{L}$. Differential blood count gives the relative percentage of each type of white blood cells. Normal value for differential

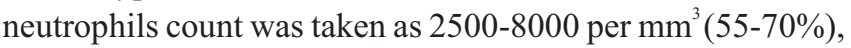
lymphocytes count was taken as $1000-4000$ per $\mathrm{mm}^{3}$ $(20-40 \%)$, monocytes count was taken as $100-700$ per $^{\mathrm{mm}^{3}}$ $(2-8 \%){ }^{7}$ The normal ranges for hemoglobin $(\mathrm{Hb})$ concentrations in adults was taken as $12-18 \mathrm{~g} / \mathrm{Dl}{ }^{8}$ All the demographic and hematologic data were entered in Microsoft excel and were analyzed.

\section{RESULTS}

A total of 100 blood samples of RT-PCR Covid-19 positive patients were received during study duration. Out of which eighty $(80 \%)$ were male and twenty $(20 \%)$ were female. Age group of patients ranged from 27 years to 94 years. Maximum number comprising of $70 \%$ of patients were above 50 years of age and none of them were below 20 years of age (Table 1).

Ninety-four (94\%) Covid-19 patients showed leukocytosis with increase in total white blood cell count above $11,000 / \mathrm{cmm}$. Out of which $25 \%$ of the patients reveal total leucocyte count above $25,000 / \mathrm{cmm}$. Highest increase TLC was observed up to $50.000 / \mathrm{cmm}$ in a 45 -year old male. Five $(5 \%)$ patients showed normal total leucocyte count and only one case $(1 \%)$ showed leucopenia revealing decrease in total leucocyte count. Ninety-six (96\%) patients showed increased differential neutrophil count. (Fig 1). Rest four (4\%) cases showed normal differential count of neutrophils. Forty-nine $(49 \%)$ of the patients revealed differential count of neutrophil more than $90 \%$ of all total WBCs. While reviewing the peripheral smears of such cases we also found toxic changes in the neutrophils in some cases. Ninety (90\%) of our Covid-19 patients showed lymphopenia. Only ten (10\%) of our patients showed normal differential count of lymphocytes. The differential monocyte count, eosinophil and basophil count 
was low. The platelets count was seen normal in seventy-eight (78\%) cases. Seven $(7 \%)$ patients showed thrombocytosis and fifteen $(15 \%)$ patients showed thrombocytopenia. Fifty-two $(52 \%)$ patients were anemic and forty-eight $(48 \%)$ patients reveal normal hemoglobin concentration. Lowest hemoglobin level observed in our study was $5.8 \mathrm{gm} / \mathrm{dl}$.

\section{Table 1. Age range of patients}

\begin{tabular}{cc}
\hline $\begin{array}{c}\text { Range of age } \\
\text { group in years }\end{array}$ & Number of patients \\
\hline $21-30$ & 7 \\
$31-40$ & 12 \\
$41-50$ & 11 \\
$51-60$ & 21 \\
$61-70$ & 24 \\
$71-80$ & 17 \\
$81-90$ & 7 \\
$91-100$ & 1 \\
Total & 100 \\
\hline
\end{tabular}

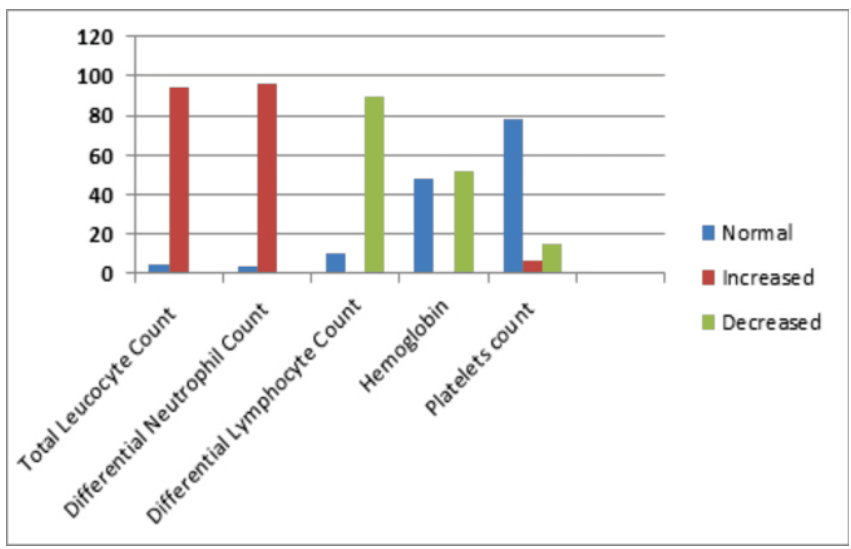

Figure 1. Variations in hematologic parameters

\section{DISCUSSION}

Eighty percent of Covid-19 positive people in our study were male. Many studies have revealed that Covid-19 is more common in men than women. Studies have shown that women have stronger immune systems compared to men. It is well known that men engage themselves in more outdoor activities ignoring physical distancing. There is also difference in life style behavior like smoking and drinking which are more common in men. ${ }^{9}$ Seventy percent of the patients in our study were above 50 years of age. Various other studies have also shown that the risk of getting Covid-19 increases with age. The reason for this could be that preexisting medical conditions like diabetes, hypertension and cardiovascular disease are more prevalent with advancing age. People suffering from these disorders are more vulnerable for Covid19 infections. ${ }^{10}$

Ninety-four percent of Covid-19 patients in our study showed leukocytosis. It was a very significant finding in our study. Studies done by Sayad B, et al showed leukocytosis was more common in patients with comorbidities like cancer, renal transplantation, hypertension, diabetes mellitus and coronary artery disease. ${ }^{11}$ Similarly, meta-analytical study done by Huang G, et al also revealed leukocytosis in critically ill patients. ${ }^{12}$ Though we have not taken the clinical history of our patients but we assume that most of the Covid-19 patients in our study were clinically ill because majority of the blood samples we received in our laboratory were from the patients admitted in Covid-19 intensive care unit or Covid ward. Also majority of the patients were above 40 years of age so they might be suffering from other disorders like diabetes and hypertension.

Neutrophils are the most abundant WBCs in human blood. They account for approximately $55-70 \%$ of all leukocytes. Increased neutrophils are seen in many pulmonary diseases associated with acute respiratory distress syndrome (ARDS). Increased neutrophils are observed in infections by influenza virus and SARS-CoV-1. Literature review shows that neutrophils play a crucial role in the pathogenesis of Covid- $19 .{ }^{13}$

Differential neutrophil count was increased in $96 \%$ of patients in our study with forty-nine (49\%) of the patients revealed differential count of neutrophil more than $90 \%$ of all total WBCs. Studies have shown that higher levels of neutrophils are seen in Covid-19 patients both in blood stream and also in lungs. ${ }^{14}$ Ninety $(90 \%)$ of our Covid-19 patients showed lymphopenia. Lymphopenia in Covid-19 patients are related with the severity of the disease. It has been studied that the mortality of Covid-19 patients increased with lower lymphocyte count. ${ }^{15}$

There was no significant change in differential monocytes count of our patients. Counts were either in normal range or lower range. Eosinophils and basophils are seen in a very low percentage in a healthy individual. We found most of our patients revealing neutrophilia and the differential eosinophil and basophil count was low. Fifty-two percentage of patients in our study were anemic. Several studies have showed increased percentage of anemia in critically ill and elderly patients with co morbidity. ${ }^{16}$ Platelets count was found to be normal in $78 \%$ cases. Studies done by Khartabil TA, et al also showed Covid-19 patients generally have normal platelet count. $^{17}$

\section{CONCLUSION}

Covid-19 infection causes changes in the hematological parameters. The parameters can provide significant clinical information about Covid-19. The major significant changes are observed in total leucocyte count. 
WHO and Nepalese Government guidelines and policies to protect an individual and community from Covid-19 infection are important. Though the vaccine against Covid-19 has been started in Nepal but because of not strictly following the Government instructions, the number of Covid-19 patients are still increasing. It remains a challenge for the Government and health workers to further stop the spread of cases in the community. Much more investigation in this field is needed. This study will help in more understanding the disease pathogenesis and thus will help the treating doctor and health worker for better management of the patients.

\section{REFERENCES}

1. Dengler L, Kuhn N, Shin DL, Hatesuer B, Schughart K, Wilk E. Cellular changes in blood indicate severe respiratory disease during influenza infections in mice. PLoS One. 2014;9(7) :e103149.

2. Hamed M.A. Hematological changes among children with dengue fever in Saudi Arabia. Egypt. J. Haematol. 2017;42: $129-133$.

3. Kularatnam GAM, Jasinge E, Gunasena S, Samaranayake D, Senanayake MP, Wickramasinghe VP. Evaluation of biochemical and haematological changes in dengue fever and dengue hemorrhagic fever in Sri Lankan children: a prospective follow up study. BMC Pediatr. 2019;19(1):87.

4. Rashmi MV, Hamsaveena. Haematological and biochemical markers as predictors of dengue infection. Malays J Pathol. 2015 Dec;37(3):247-51.

5. Aziz N, Quint JJ, Breen EC, Oishi J, Jamieson BD, MartinezMaza O, Detels R. 30-Year longitudinal study of hematological parameters of HIV-1 negative men participating in Los Angeles multicenter AIDS cohort study (MACS). Lab Med. 2019 ;50(1):64-72.

6. Mo Yang, Margaret HL Ng, Chi Kong Li. Thrombocytopenia in patients with severe acute respiratory syndrome (review). Hematology. 2005;10:2:101-105.

7. Walker HK, Hall WD, Hurst JW, editors. Clinical Methods: The White Blood Cell and Differential Count. In The History, Physical, and Laboratory Examinations. 3rd edition. Boston: Butterworths; 1990. Chapter 153. Available from: https://www/mcno/nlm.nih.gov/books/NBK261

8. Kathleen Deska Pagana, PhD, RN, Timothy J. Pagana, MD, FACS and Theresa Noel Pagana, MD, FAAEM Mosby's Diagnostic and Laboratory Test Reference - Elsevier eBook on Vital Source, 14th Edition.

9. Bwire GM. Coronavirus: Why men are more vulnerable to Covid-19 than women? SN Compr Clin Med. 2020:1-3.
10. Biswas M, Rahaman S, Biswas TK, Haque Z, Ibrahim B. Association of sex, age, and comorbidities with mortality in COVID-19 patients: A systematic review and meta-analysis. Intervirology. 2021;64:36-47.

11. Sayad B, Afshar ZM, Mansouri F, Rahimi Z. Leukocytosis and alteration of hemoglobin level in patients with severe COVID19: Association of leukocytosis with mortality. Health Sci Rep. 2020;3:e194.

12. Huang G, Kovalic AJ, Graber CJ. Prognostic value of leukocytosis and lymphopenia for Coronavirus disease severity. Emerg Infect Dis. 2020;26(8):1839-1841.

13. Camp JV, Jonsson CB. A role for neutrophils in viral respiratory disease. Front Immunol. 2017;8:1.

14. Buja, LM, Wolf DA, Zhao B, Akkanti B, McDonald M, Lelenwa L, Reilly N, Ottaviani G, Elghetany MT, Trujillo DO, Aisenberg GM, Madjid M, Kar B. The emerging spectrum of cardiopulmonary pathology of the coronavirus disease 2019 (COVID-19): Report of 3 autopsies from Houston, Texas, and review of autopsy findings from other United States cities. Cardiovascular Pathology. 2020;48. Article 107233.

15. Muhammad Shahbaz, et al. Clinical significance of lymphopenia in older patients with Covid-19. GM. 08 July 2020.

16. Petek Eylul Taneri, Sergio Alejandro Gómez-Ochoa, Erand Llanaj, Peter Francis Raguindin, Lyda Z. Rojas, Beatrice Minder Wyssmann, Doris Kopp-Heim, Wolf E. Hautz, Michele F. Eisenga, Oscar H. Franco, Marija Glisic, Taulant Muka. Anemia and iron metabolism in COVID-19: A systematic review and meta-analysis. medRxiv 2020.06.04.20122267.

17. Khartabil TA, Russcher H, van der Ven A, de Rijke YB. A summary of the diagnostic and prognostic value of hemocytometry markers in COVID-19 patients. Crit Rev Clin Lab Sci. 2020 Sep;57(6):415-431. 